\title{
Black coal, thin ice: the discursive legitimisation of Australian coal in the age of climate change
}

\author{
Roman Stutzer ${ }^{1,5}$, Adrian Rinscheid (1) ${ }^{2}$, Thiago D. Oliveira ${ }^{1}$, Pedro Mendes Loureiro (D) ${ }^{3}$, Aya Kachi (1) ${ }^{1 凶} \&$ \\ Mert Duygan 1,4
}

Despite mounting urgency to mitigate climate change, new coal mines have recently been approved in various countries, including in Southeast Asia and Australia. Adani's Carmichael coal mine project in the Galilee Basin, Queensland (Australia), was approved in June 2019 after 9 years of political contestation. Counteracting global efforts to decarbonise energy systems, this mine will substantially increase Australia's per capita $\mathrm{CO}_{2}$ emissions, which are already among the highest in the world. Australia's deepening carbon lock-in can be attributed to the essential economic role played by the coal industry, which gives it structural power to dominate political dynamics. Furthermore, tenacious networks among the traditional mass media, mining companies, and their shareholders have reinforced the politicoeconomic influence of the industry, allowing the mass media to provide a venue for the industry's outside lobbying strategies as well as ample backing for its discursive legitimisation with pro-coal narratives. To investigate the enduring symbiosis between the coal industry, business interests, the Australian state, and mainstream media, we draw on natural language processing techniques and systematically study discourses about the coal mine in traditional and social media between 2017 and 2020. Our results indicate that while the mine's approval was aided by the pro-coal narratives of Queensland's main daily newspaper, the Courier-Mail, collective public sentiment on Twitter has diverged significantly from the newspaper's stance. The rationale for the mine's approval, notwithstanding increasing public contestation, lies in the enduring symbiosis between the traditional economic actors and the state; and yet, our results highlight a potential corner of the discursive battlefield favourable for hosting more diverse arguments.

\footnotetext{
${ }^{1}$ Faculty of Business and Economics, University of Basel, Basel, Switzerland. ${ }^{2}$ Institute for Economy and the Environment, University of St. Gallen, St. Gallen, Switzerland. ${ }^{3}$ Centre of Latin American Studies and Department of Politics and International Studies (CLAS-POLIS), Fitzwilliam College, University of Cambridge, Cambridge, UK. ${ }^{4}$ Department of Environmental Social Sciences, Swiss Federal Institute of Aquatic Science and Technology (Eawag),

Dübendorf, Switzerland. ${ }^{5}$ The authors are reverse alphabetically ordered. ${ }^{凶}$ email: aya.kachi@unibas.ch
} 
M itigating climate change requires not only the development of low-carbon innovations, but also efforts to steer the decline of fossil fuel-based technologies, infrastructures and related systems (Rosenbloom and Rinscheid, 2020). The need for the decline is apparent when it comes to coal, the single largest source of global temperature increase (IEA, 2019) and responsible for $27 \%$ of the world's primary energy supply in 2018 (BP, 2019). In fact, the members of Powering Past Coal Alliance (PPCA), a coalition of $100+$ countries, sub-national jurisdictions and organisations, have committed to phasing out coal-fired power generation by 2030 .

PPCA does not, however, include the world's major coal consumers (Jewell et al., 2019), and continued investment into coal in many countries is leading to ongoing carbonisation of energy systems (Cui et al., 2019; Edenhofer et al., 2018; Steckel et al., 2015, 2020). This deepening carbon lock-in is sustained by a variety of factors, which prominently include economic actors that draw private benefits from the continued use of fossil fuels (investors, utility companies, mining companies and so on) (Hess, 2014; Kim et al., 2016; Trencher et al., 2021; Unruh, 2000). In Australia, a significant new coal mine project was approved in June 2019 in the Galilee Basin, Queensland. Coal businesses are at the centre of Australian politics due to the historical alliance between state and industry (Baer, 2016; Crowley, 2013). Moreover, the Australian political economy has become transnationalised due to the country's embeddedness in international coal trade (Rosewarne, 2016). Therefore, international businesses such as Adani Group, the Indian multinational conglomerate that applied for developing mines in the Galilee Basin in Queensland, have become an integral part of the Australian energy regime. As such, this mine deepens the links between Australia and India, respectively the world's largest exporter and second-largest importer of coal (data from UNComtrade).

Given the mounting climate awareness among investors and the broader public, energy incumbents have been increasingly subject to public pressure (Curran, 2020). These corporations currently suffer a 'legitimacy gap' (Hobbs, 2020), which has led them to adopt intransigent strategies to secure the profitability of their business models. They thus use various strategies to defend their economic interests, most of which ultimately target the formulation of public policies (Bell and Hindmoor, 2014; Nyberg and Murray, 2020). While some strategies-often referred to as 'inside lobbying'-directly target parties and governments, another set of strategies-called 'outside lobbying' - uses public relations campaigns and media coverage with the aim of shaping policy outcomes and public perception of the industry (Hillman and Hitt, 1999; Weiler and Brändli, 2015).

In the context of policy efforts against climate change and backlash from incumbents, the overarching question that frames our research concerns the economic, social and political structures, processes and agents that allow these industries to continue operating. Focusing on practices of discursive legitimisation, we approach this question from a political economy perspective, exploring to what extent sections of the traditional media and of the Australian state operate as hegemony-building vehicles for the coal industry, and whether this continues to hold broader traction. This leads to two specific, narrower questions, which we unpack in light of this framing. We ask, first, whether the environmental narratives of the mainstream media, in both its corporate and state-funded branches, differ from sentiments expressed on Twitter. Second, we ask whether the association between these narratives and sentiments has changed over time, looking into the dynamics of the coal industry's attempt to secure a social license to operate. Both questions are interpreted in light of the key public-policy decisions of the studied period.
We study public contestation surrounding Adani's Carmichael coal mine approval, looking into both traditional news and social media. First, to ascertain the role of 'traditional' channels of outside lobbying, we investigate to what extent the Courier-MailQueensland's most relevant publicly-traded ${ }^{1}$ news medium - has advanced pro-coal narratives in its coverage of the coal mine. Second, we study whether coverage of the coal mine in the Courier-Mail converges with public sentiment as expressed on Twitter and we track the evolution of public opinion over time. While traditionally public opinion has been studied through surveys, using Twitter data allows us retrospectively to measure the evolution of key-if not necessarily representative-dimensions of public opinion based on a massive dataset.

Our analysis reveals that public policy and traditional media coverage differed markedly from public opinion. Coverage of the mine was decidedly pro-coal in the Courier-Mail, and thus well aligned with the main thrust of the relevant public-policy decisions taken in 2019. Yet public opinion, as measured through Tweets, has become more pro-climate/anti-coal over time. This may lead to questioning whether there is a social licence to operate the Carmichael coal mine. More broadly, our study exemplifies how natural language processing techniques can enhance our understanding of public discourse in the realm of climate policy. Our study has implications for policymakers, stakeholders, and activists. While traditional media often underplays the effects of climate change (Boykoff and Boykoff, 2007), such discussions are much more prominent in social media (Boykoff, 2011). Therefore, with the general public increasingly shifting to social media as a source of information, ${ }^{2}$ and with mining, energy and media companies shifting their strategies to it with legitimate and covert methods (Hobbs et al., 2020), social media consolidates itself as a privileged arena to dispute narratives and, eventually, outweigh the influence of incumbent corporations on public opinion.

\section{The political economy of coal in Australia}

The Australian state has a close and long-standing relationship to mining, which can be traced back to the discovery of coal in the late 18th century. In his historical account of the emergence, consolidation, and corporatisation of the nexus between the state and the coal industry in Australia, Baer (2016) shows that the former has actively sponsored the latter since its inception by offering subsidies and granting monopoly rights to companies. Over the centuries, this relationship has evolved and is now transnational in character (Rosewarne, 2016), with coal representing a core sector of the Australian economy and its international economic insertion. Recently, with climate change becoming a major concern, the role of coal has gained a further layer of complexity in the contested attempts to grant it public legitimacy (McKnight and Hobbs, 2013). To understand the possibilities of combating climate change, it is thus necessary to explore the political economy of coal, the Australian state, and the discursive processes that permeate them.

At one level, the relationship between the coal industry and the Australian state can be approached as an instance of the more general relationship between the state and economic groups. This requires unfolding our understanding of both the state and business, in order to identify the groups and sectors with greater economic and political power. For this, the Regulation Approach to political economy proposes the concepts of 'accumulation regimes' and 'modes of regulation' (Jessop and Sum, 2006). The former refers to the key drivers of a country's economy, including its leading sectors, and interconnections between them. The latter in turn refer to the wider social relations and institutions that are 
necessary for the accumulation regime to reproduce itself-i.e. the non-economic underpinnings of economic growth-in which the state and discursive processes are central.

The economic sectors capable of driving growth or sustaining a country's insertion into the global economy can exert structural power in a given accumulation regime, of which coal in Australia is a clear example. Large, macroeconomically important sectors have, at this level of the argument, a power that does not depend on how they influence politics on a daily basis (Offe and Wiesenthal, 1980). In this vein, during the 2010s, coal represented on average $17.3 \%$ of the value of Australia's exports, whilst fuels more broadly represented $28.7 \%$ (respectively $20.2 \%$ and $35.2 \%$ in 2018; data from UNComtrade). This process began in the 1950s, initially due to Japan's reconstruction efforts after World War II, leading Australia's black coal exports to increase from 1.9 megatons (Mt) to $95.7 \mathrm{Mt}$ between 1960 and 1986 (Thurber and Morse, 2015). In 1984, it became the world's largest coal exporter, and with this dependence came a reorganisation of the state/coalindustry nexus (Bell and Hindmoor, 2014). As Australia became increasingly embedded in the international economy, with the role of a mineral and fuel provider, the economic sectors providing these goods acquired greater leverage in the political process. This accompanied Australia's turn towards economic liberalism, marking a shift away from the protectionist stance that had hitherto characterised it. Consequently, the possibility of capital flight, disinvestment and similar 'threats' from the coal industry-partially enabled by state-promoted economic liberalisation-allowed it to constrain policy-making in its favour.

Extending beyond its structural power, the mining industry in Australia also influences policy-making through lobbying and direct participation in formulating policies. As such, donations from the mining industry to the major national parties between 2006 and 2016 amounted to 16.6 million AUSD (Aulby, 2017). Furthermore, in a revolving-doors scheme between government and the private sector, executives from fossil-fuel industries have regularly participated in formulating relevant policies for the sector (Baer, 2016; Pearse, 2009). In what is perhaps the most emblematic case, Brendan Pearson was made senior adviser to Scott Morrison, the Australian Prime Minister, in June 2019 (Hobbs, 2020; Vorrath, 2019). Brendan Peason is the former CEO of the Minerals Council of Australia, which represents some of the largest mining conglomerates in the world, including Adani Mining, and is intransigent enough in its views on climate change and coal to make even large incumbent companies, like BHP and Rio Tinto, review their association to the Council. In this process, the almost symbiotic arrangement between the fuel industry and the state and government officials exploits the specificities and fault lines of Australia's political system, including its federal system and the geographically variable role that coal and the wider mining economy play (Hobbs et al., 2020). These arm's length arrangements further secure the privileged role of the fuel sector in the Australian state-leading, amongst others, to the third-highest level of subsidies in the world for domestic coal consumption, 870 million USD per year (Gencsu et al., 2019).

Leveraging this structural power, and as an attempt to safeguard and advance it, the coal industry conducts a series of hegemony-building exercises in Australia-as well as throughout the global political economy. Hegemony, in this context, means to go beyond the simple dominant position of the leaders in an accumulation regime by undergirding it with perceived legitimacy. At its core, building economic hegemony is thus being able to attempt to present the interests of a certain group as those of wider society (Jessop, 2003). Perhaps the clearest example is when Charles Wilson, an executive of General Motors who President Eisenhower nominated Secretary of Defence in 1953, said that 'what was good for [the US] was good for General Motors, and vice versa' (Fogel et al., 2008). Although the negative environmental and social externalities generated by mining (Della Bosca and Gillespie, 2018; Phelan et al., 2017; Vela-Almeida et al., 2015) prevent it from reaching such a hegemonic position, striving towards it and attempting to secure a social license to operate is all the more necessary in light of the ensuing contestations-i.e. the industry's legitimacy gap.

Hegemony-building in this context can be approached through the public relations campaigns and 'outside-lobbying' activities of the sector. These campaigns are mainly organised by the Australian Coal Association, the Mineral Council of Australia, and the Australian Trade and Industry Alliance (and, as argued in the fourth section, they also include sections of the traditional media). Similar to inside-lobbying, public-relations campaigns are also geared to exerting maximum influence by exploiting the geographical, social and political variability of public opinion in the Australian federation, aiming to convince key sections of the public whilst disregarding their effect on politically marginal ones (Hobbs et al., 2020). These campaigns often aim at local communities and seek to obscure and downplay the wider effects (e.g. climate change) of coal mining, driving an overall intransigent strategy of resistance to change aimed at securing the industry's privileged role in Australia's political economy by making other actors and institutions adapt to its needs (Hobbs, 2020). Such campaigns offer a partial explanation for the Labour Party's failure in approving policies to reduce greenhouse gas emissions between 2008 and 2013 (McKnight and Hobbs, 2017). Tropes such as 'energy poverty' and 'clean coal' came to dominate the public debate about coal between 2014 and 2017, arguably because the very complexity of climate change facilitates the emergence and diffusion of simplistic narratives that evade its multifarious nature (Curran, 2021; Demetrious, 2019).

Through these processes-the structural power of core economic sectors, inside and outside lobbying, and networks of access to power-corporations, and particularly coal mining ones, can exert an inordinate influence on policy-making in Australia that bypasses electoral channels. Differently from 'ordinary citizens', who can attempt to influence policy through prospective and retrospective voting, and organised civil society, which can apply pressure via social movements and similar organisations including social-media based ones (Brym et al., 2014), business groups have a variety of tactics at their disposal. They straddle different paths, including the political system of the country and exploiting which electoral results are the most politically relevant, but ultimately operate outside of the electoral arena. It should be said that, in general terms, this is not specific to Australia: see, for example, the strong evidence that policy-making in the US is much more responsive to corporations and high-income groups than to the preferences of median-income citizens (Gilens and Page, 2014; Winters and Page, 2009). In the case of Australia, more specifically, the implications are that there is a strong symbiosis between the state and the coal industry, hampering attempts to combat climate change even when the population largely favours them. As the lobbyist-turned-senior-advisor Brendan Pearson said, 'To be honest, [coal isn't a divisive political issue] when you look at [the] two major [political] parties [in Australia]' (Hobbs, 2020).

In this vein, the approval of Adani's Carmichael coal mine in June 2019, which paved the way for the opening of several mines in the Galilee Basin, represents a huge setback in terms of Australia's efforts to mitigate climate change-but one closely aligned to the dynamics of the country's accumulation regime. The mine will operate in Queensland and has the potential of becoming one of the largest coal mines in the world. Although several studies show that Adani's project will most likely become a stranded asset, such assessments fall short in that they consider the coal 
mine as a stand-alone business, rather than an integral part of India's industrial development plans (Rosewarne, 2016). As such, cost-benefit analyses of the mine's viability are ineffective in convincing policymakers: even if Adani's Carmichael coal mine is not financially sound in itself, it may still be a worthwhile venture when put in its wider context. Indeed, coal-based growth is a key element of India's and Australia's accumulation regimes and modes of regulation.

Approaching climate policies through the lens of political economy has the advantage that economic growth and investment, alongside their material underpinnings and implications, are conceptualised as socially embedded phenomena. Economic processes and their articulation to climate change thus cannot be studied in isolation, or in purely financial or environmental technical terms, but must rather be seen as dependent on, and intertwined with, wider social institutions (Jessop and Sum, 2006). This article unpacks a specific link in this nexus: how sections of the traditional media in Australia are part of the country's mode of regulation. They are tied to the coal industry and attempt discursively to legitimate the latter, even-or especially-when against popular opinion. News Corp's one-sided coverage of coal plays an important role in legitimising Australia's longstanding subordination to the coal industry, guaranteeing that business remains as usual when it comes to coal and $\mathrm{CO}_{2}$ emissions. The corporation is linked to coal companies through a common network of shareholders, and it blatantly advances procoal narratives based on arguments that eschew scientific evidence, as shown in the fourth section after presenting the methods and data used in this research.

\section{Data and methods}

Throughout our empirical studies, we used data from Factiva, LexisNexis, and Twitter. Our empirical analysis in the following section starts with an illustration of the close tie between News Corp and Australia's coal industry. To do so, information about the shareholders of News Corp and mining companies was collected on Factiva in December 2019. Later in the central part of our empirical analyses, we conduct quantitative text analyses using news and Twitter contents, which requires a large datacollection and -processing effort. This section presents the data collection, processing and analysis methods.

Articles from the Courier-Mail and online news articles from the $A B C$ were downloaded from LexisNexis. It is important to notice that while the Courier-Mail is a newspaper in the traditional sense, the $A B C$ is predominantly a broadcast service (TV and radio) which also runs a daily news website. Hence, although our results may be sensitive to these differences in the outlets, the $A B C$ was the best proxy we could find for what one could consider as an independent outlet', i.e. as a benchmark against which we contrast Courier-Mail, which essentially served as a special interest group. In order to compute the evolution over time of the semantic similarity between these news outlets and tweets, one needs a sample in the order of thousands of documents. Since the majority of Australia's newspapers are owned by either News Corp or Nine/Fairfax, the only options as proxies for independent outlets were $A B C$ and The Guardian. We opted for the former because, according to a Roy Morgan survey, $A B C$ is the online news portal with the thirdhighest number of online monthly visits. (For further data on the characteristics of the outlets, see http://www.roymorgan.com/ findings/7595-top-20-news-websites-march-2018-201805240521.)

In the remainder of the section, we will first describe how we constructed the text database from the news outlets and tweets. We then explain latent semantic analysis (LSA), a class of methodologies that allows us to assess the evolution of the semantic similarity between these texts.
Concerning the news outlets, the Courier-Mail and the $A B C$, we have selected all articles containing both words Adani and coal. Tweets were scraped using Python's package getoldtweets. We downloaded all tweets using the hashtag StopAdani and all tweets containing the words Adani and coal, excluding tweets using the hashtag StopAdani. We have used geolocation in order to select only Tweets from Australia, filtering replies and retweets. After gathering relevant tweets, we also removed the words Adani, coal, and \#StopAdani. Although keeping them would not make any qualitative difference in our conclusion, one must consider the fact that words that appear very often receive little weight due to how the weight is computed with the term frequency-inverse document frequency (TF-IDF), which will be explained later in the present section. We chose to remove these frequently-appearing words precisely due to our tweet selection criterion to avoid the risk that documents within each group would be more similar than they actually are merely for sharing the hashtag or because they share the words Adani and coal.

We then cleaned the text database by removing all duplicated articles and tweets. The documents went through standard preprocessing procedures for quantitative text analysis; namely, numbers, punctuation, and stop words were removed, Porter's stemmer was used to remove common suffixes, and all letters were converted to lower case. The data and codes for replication are available on our GitHub repository. ${ }^{3}$

Next, we turn to LSA, a method that treats text as data and allows us to determine the similarity of documents quantitatively. In our analyses, we use LSA to compute the evolution of the semantic similarity between traditional news and tweets. Similar to factor analysis, LSA identifies the underlying factors that help to explain the correlation of the observed variables. In this sense, the semantic similarity of two documents reflects shared latent ideas, such as rhetorical devices, discourses, ideologies, and so forth.

The term-document matrix was weighted using the TF-IDF given by

$$
T F_{t d} \log \left(N / D F_{t}\right)
$$

where $T F_{t d}$ is the frequency of term $t$ in document $d$, i.e. the total number of occurences of each term divided by the total number of words in each document. $N$ is the total number of documents, and $D F_{t}$ is the number of documents containing the term $t$. TFIDF selects terms that are meaningful by penalising terms that are common to too many documents, i.e. the higher is the number of documents in which a term appears the lower is the weight given to it. Therefore the weight of a term increases as its frequency increases in a particular document, but it decreases the more common it is across documents.

Formally, LSA works by running a singular value decomposition on the term-document matrix $M$, which consists of an approximation of the original term-document matrix as the product of three matrices:

$$
M \approx U_{k} \sum_{k} V_{k}^{\mathrm{T}}
$$

where $U$ is the matrix of the terms, $V$ is the matrix of the documents, $\Sigma$ is a diagonal matrix with the strength of the dimensions, and $k$ is the number of dimensions.

Therefore, it is a data-driven algorithm that approximates as closely as possible the original matrix; the elements in the diagonal of $\Sigma$ are the latent factors that explain the correlations between words: these may be underlying concepts, topics, or narratives that explain why words co-occur in the papers. Rather than predetermining a set of concepts or topics, the method uses the matrix decomposition to identify abstract dimensions that best fit the data, and the similarity of the papers depends on their loadings in these dimensions. Since each paper is a vector with 
many dimensions, we calculated the cosine similarity between all pairs of papers. The cosine similarity between two documents is given by the dot product of the vectors over the product of their magnitude:

$$
\frac{\vec{u} \cdot \vec{v}}{\vec{u} \vec{v}}
$$

Typically scholars use between 100 and 300 dimensions to run the LSA. To create the semantic maps (Fig. 2), we used 200 dimensions. For robustness we have also run the analysis with 100 and 300 dimensions, obtaining very similar results. In order to plot the two groups of tweets and the Courier-Mail in a twodimension semantic space, we used multidimensional scaling (MDS). This was done by first computing the cosine similarity of all pairs of documents and then using MDS to reduce the matrix from 200 to 2 dimensions. To compute the monthly semantic similarity between adanitweets and StopAdani (Fig. 3) we used 50 dimensions. This number was chosen because there are less than 2000 observations in some months. Given the sample size, a higher number of dimensions would likely cause overfitting. As a robustness check we have also run the analysis using 100 dimensions and the trend was still significantly positive at $5 \%$.

News Corp and the discursive legitimisation of coal. In the runup to the approval of Adani's Carmichael coal mine, advocates put forward a number of rhetorical devices and pro-coal narratives with the objective of legitimising the use of coal (e.g. by instilling the idea that mining is part of Australia's identity) and delegitimising the case for climate change mitigation (e.g. by bringing into question empirical evidence from climate science). Oxymora such as 'sustainable mining', 'clean coal', and 'ecoterrorism' were among the most popular rhetorical devices used by coal incumbents. Upon closer inspection, many arguments of the pro-coal discourse do not withstand scientific scrutiny. For example, the number of jobs that would be created and the relative importance of mining for Queensland's economy were overstated, and the environmental impact of mining and the risks to the Great Barrier Reef were downplayed (Blondeel and Van de Graaf, 2018; Brevini and Woronov, 2017; Curran, 2020). Moreover, coal mine proponents often made the moral argument that exploiting the mine was important for India's energy security and, consequently, for the country's poverty-reduction agenda (Rosewarne, 2016).

Previous studies have shown that in the early 2000s climate change was typically framed as controversial by the US media (Antilla, 2005), and that the influence of contrarian groups over major news outlets has increased between 1993 and 2013 (Farrell, 2016). However, climate-change denial in US newspapers has decreased considerably after Hurricane Sandy in 2012 (Cody et al., 2017). In contrast to the US, the Australian media landscape seems much more impervious to scientific evidence about the imperative for new radical social policies (D'Alessandro et al., 2020). News Corp, a major mass-media firm, owns several of the most important media outlets in Australia, which makes it an important information gatekeeper in 'one of the most concentrated' information markets in the world (Newman et al., 2017). The concentration of power that comes along with this role sets limits to democratic processes in the country (McKinnon et al., 2019; McNair et al., 2017; Noam, 2016; Tiffen, 2015). In order to get a better sense of News Corp's intertwining with the coal industry, we used data from Factiva (as of December 2019) to compile a shareholder matrix of News Corp and of major coal companies operating in Australia.

As Table 1 shows, there is considerable overlap between News Corp's shareholders and those of the main mining companies.

\begin{tabular}{|c|c|c|}
\hline & $\begin{array}{l}\text { The Vanguard } \\
\text { group (\%) }\end{array}$ & $\begin{array}{l}\text { BlackRock fund } \\
\text { advisors (\%) }\end{array}$ \\
\hline \multicolumn{3}{|c|}{ Mass media company } \\
\hline News Co & 13.81 & 5.09 \\
\hline \multicolumn{3}{|c|}{ Mining companies } \\
\hline Adani & 0.84 & - \\
\hline Peabody & 7.45 & 4.91 \\
\hline $\mathrm{BHP}$ & 3.98 & 4.26 \\
\hline Wesfarmers & 4.23 & 2.08 \\
\hline Rio Tinto & 5.55 & 4.49 \\
\hline New Hope & 0.75 & - \\
\hline Glencore & 2.29 & 1.35 \\
\hline Banpu & 2.96 & 1.61 \\
\hline Whitehaven & - & 3.12 \\
\hline
\end{tabular}

The Vanguard Group and the BlackRock Fund Advisors own, respectively, $13.81 \%$ and $5.09 \%$ of News Corp. These two investment groups own shares in most of the top mining companies operating in Australia; Vanguard has substantial investments in eight out of the nine companies listed, while BlackRock holds shares in seven of them. Therefore, mining companies are directly connected to News Corp, and they are also indirectly connected through a common pool of shareholders. ${ }^{4}$

This network formed by News Corp, mining companies, and shareholders provides the background against which to interpret the results of our content analysis shown below. In particular, we hypothesise that this network of special interests engenders a dominance of pro-coal perspectives in News Corp's media outlets. This need not happen through direct, personal influence: even if News Corp's major shareholders do not explicitly influence the contents of newspaper articles, they nevertheless have power over the corporation through the latent threat that they will divest from the company should it shift its long-standing stance on coal. Coal interests thus have a form of structural power over News Corp, the two being connected by interlocking financial ties. Moreover, such financial ties represent and reinforce a social network of elite groups which hold considerable power over public policies, as discussed in the second section.

In order to investigate the extent to which News Corp has advanced pro-coal narratives, we compared coal-related articles of Courier-Mail and $A B C$. The former is the widest-circulation regional newspaper of News Corp in Queensland, where the Carmichael coal mine will operate. The latter is a state-owned online news portal, which does not depend on revenue from advertisement and shareholders' investment decisions; therefore, we expect it to be less influenced by mining companies. It is not our intention to claim that $A B C$ is non-ideological with respect to coal policy; our aim is to assess whether media coverage about the Carmichael coal mine differs considerably in the two outlets, in light of their distinct business structures.

We downloaded all news articles containing both words Adani and coal between March 2017 and February 2020 from CourierMail and $A B C$. March 2017 was the starting period as it was the first month with a considerable number of tweets containing the hashtag \#StopAdani, used in the next section. To investigate which arguments are more frequent in the news outlets we chose 18 expressions that refer to environmental topics, economic factors, the importance of science, and social mobilisation. We have also done this exercise with The Australian, a national newspaper News Corp owns but did not include it since results were quite similar to Courier-Mail. 


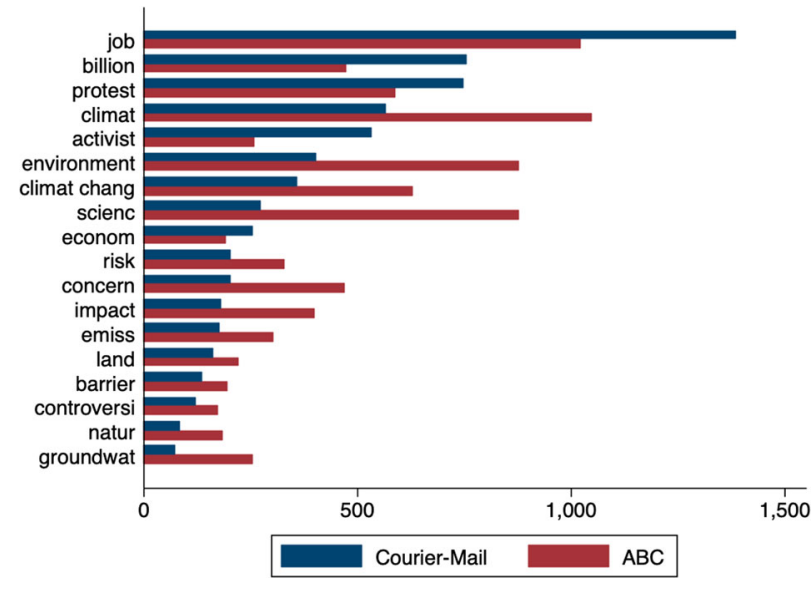

Fig. 1 Environmental topics and scientific arguments are much more common in ABC than in Courier Mail, which is a corporate media outlet. Word count adjusted by the number of news articles and words per article, Source: Lexis-Nexis.

Figure 1 shows the adjusted word count controlling for the difference in the number of articles. For the category 'science', note that we have aggregated several words related to the concept, such that it includes the words data, scienc, scientist, scientif, geoscienc, research, and professor. No other categories have been aggregated. Our criterion to choose the words was based on how often they appeared in news articles, and we selected words that relate to the environment, to the economy, or to social mobilisation. Given that there were more news articles in Courier-Mail (961 articles) than in $A B C$ (272 articles), and that the average word count of articles is different in the two outlets, we multiplied the word count of $A B C$ by the total number of words in Courier-Mail divided by the total number of words in $A B C$.

Results indicate that $A B C$ is much more concerned about environmental topics and more willing to mention scientific evidence than Courier-Mail. Notice that words such as climate, environment, concern, and science are much more common in $A B C$, while Courier-Mail seems to privilege an economy-centred narrative with a higher prevalence of words such as job, billion, and economy. Finally, somewhat surprisingly the words 'protest' and 'activist' are more common in Courier-Mail. However, previous research has shown that pro-Adani narratives often frame social movements as 'eco-terrorism' in order to delegitimise them, which may explain this higher prevalence.

It should be noted that this pattern of delegitimising opponents, particularly when environmental concerns are invoked, is a common practice across many companies in the mining sector (Kirsch, 2014). This extends beyond Australia and has become, for example, a key debate in the Latin American political economy of recent decades. In the continent, a renewed extractivist push has spurred growing popular contestation against its environmental, social and cultural impacts, in turn prompting backlashes from mining corporations-which, as a rule, are backed by the state and its repressive apparatus, even when under left-of-centre administrations (Gudynas, 2009; Svampa, 2013). Hence our empirical results not only support previous findings based on qualitative discourse analysis (Brevini and Woronov, 2017; Curran, 2020), but they are also congruent with our hypothesis that the network of special interests is correlated with the pro-coal attitude of News Corp's outlets, which are part of the broader political and discursive underpinnings of Australia's pattern of economic growth.
Measuring collective sentiment expressed on Twitter. Social media is an important site for the construction of social identities (Zhao et al., 2008). Discussion about climate change on Twitter is marked by appeals to scientific evidence, and such debates are likely to influence public opinion (O’Neill et al., 2015). Although individuals tend to socialise with like-minded individuals, creating echo-chambers where dialogue between groups holding opposite views is restricted (Hobbs et al., 2020), there is a fair amount of exchange between people with different positions (Williams et al., 2015). Indeed, the evidence suggests that people using social media are more exposed to opinions that differ from their own than people not using social media (Newman et al., 2020). The internet thus has implications for both politics and climate scientists; as a technology that is becoming politically normalised, climate policies are expected to be increasingly influenced by online debates (Farrell, 2012). Therefore, Twitter data, if not directly representative of wider society, nevertheless carry important information as they highlight the sentiments of a group of social media users that tend to be both politically active and opinion-leaders within their respective spheres.

To assess whether collective sentiment expressed on Twitter has become more or less supportive of Adani's Carmichael coal mine, we scraped two groups of tweets between 2017 and 2020: \#StopAdani tweets are all tweets containing the hashtag StopAdani (84,784 tweets) while Adani tweets are all tweets containing the words Adani and coal, excluding tweets using the hashtag StopAdani (29,402 tweets). Our strategy was thus to exploit the anti-coal stance of people using the hashtag StopAdani, on the one hand, and the pro-coal stance of Courier-Mail, on the other, as benchmarks to evaluate whether collective sentiment in all other tweets about Adani Carmichael changed during the period. We start our analysis in March 2017 since that was the first month with a significant amount of tweets containing the hashtag StopAdani. While News Corp's biased coverage of Adani's Carmichael coal mine has arguably contributed to the approval of the mine, it is worth investigating how collective sentiment in the Twittersphere compares with the news coverage and whether it diverged from the typical narratives of the mainstream media over time.

In order to do so, we apply LSA to tweets and news articles between 2017 and 2020. LSA is a method for uncovering underlying relationships between a large number of words or documents (Deerwester et al., 1990). The method uses singular value decomposition and calculates cosine similarity scores between all pairs of texts to determine their semantic similarity (see the section "Data and methods"). An advantage of LSA relative simply to analysing the co-occurrence of words is that even two documents that do not have any word in common will be identified as conceptually related if the words used in these documents appear in similar contexts. Hence, if documents $\mathrm{A}$ and $\mathrm{B}$ share a great number of words with document C, LSA is able to identify the similarity of A and $\mathrm{B}$ through their mutual relationship with $\mathrm{C}$.

Figure 2 shows the results for two periods: March 2017-October 2017 and December 2019-February 2020 (2017 and 2020 henceforth). These periods were chosen based on the results of structural break tests (see Supplementary Information). In order to plot the documents in the semantic space, we reduced the cosine similarities to two dimensions using multidimensional scaling. Due to the high number of tweets relative to news articles we randomly selected $10 \%$ of the tweets. Furthermore, to make the visualisation clearer we only plot tweets and news articles that are within one standard deviation of each group's centre.

Comparing the two waves, results indicate that both Adani tweets and \#StopAdani tweets became less similar to Courier-Mail. While the average position of Courier-Mail has not changed over time, revealing this source's inertia, that of Adani tweets and \#StopAdani tweets have shifted away from it. Our interpretation of this result is 


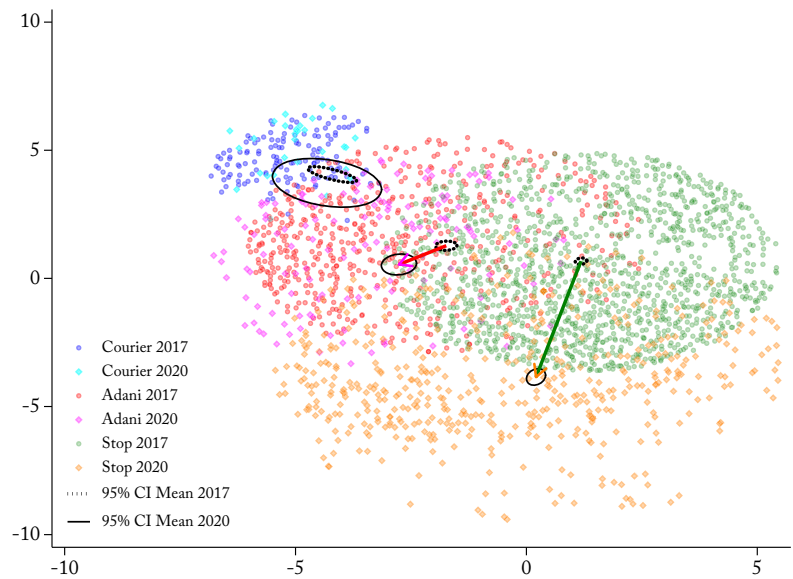

Fig. 2 The map shows the evolution of the similarity between explicitly anti-coal tweets using the hashtag \#StopAdani (Stop) and general tweets related to Adani Carmichael (Adani), distant from the pro-coal position of Courier-Mail (Courier). Semantic map, March 2017-October 2017 vs. December 2019-February 2020.

that News Corp has been less able to shape public perception about coal in the last 3 years. Since Twitter influences public opinion both directly and indirectly (Farrell, 2012; O’Neill et al., 2015; Williams et al., 2015), growing opposition to Adani's Carmichael coal mine on Twitter should lead to a shift in public opinion in the same direction-although, as explained in the section "The political economy of coal in Australia", this might be insufficient to overcome corporate channels of influence over policy-making.

Next, we compute the semantic similarity between Adani tweets and \#StopAdani tweets for each month between March 2017 and February 2020. As Fig. 3 shows, the semantic similarity between the two groups steadily increased over the last 3 years, apart from a significant drop following the approval of the mine, peaking in January 2020. Indeed, the trend is positive and significant at $1 \%$. Therefore, over the last 3 years opinions expressed by people tweeting about Adani's Carmichael coal mine have become statistically more similar to opinions expressed by people using the hashtag StopAdani. Our interpretation of this result is that environmental awareness has been increasing in recent years among our group of interest, namely Adani tweets, which have distanced themselves from mass-media narratives.

\section{Discussion}

The results of our analysis suggest that (1) News Corp functions as a channel of the coal industry's outside lobbying activities that help to legitimise the status quo, while (2) environmental awareness on Twitter has increased over the last 3 years. The approval of Adani's Carmichael mine in spite of increasing public pressure indicates the enduring symbiosis between the Australian state and the coal industry, which remains a key factor in the country's hesitance to reduce its reliance on coal and its transnational circuits. This leads to further questions about the extent to which public policies are responsive to public opinion, as opposed to corporate channels of access to power.

This paper presented a new approach to measuring the evolution of collective sentiment on Twitter over time that may be useful for scholars investigating how political outcomes depend on the triad of stakeholders, media, and public opinion. Our empirical strategy was to compute the semantic similarity between two groups of tweets about Adani's Carmichael coal mine and news articles. We compared the position in the semantic space of Adani tweets with two other groups whose stance on coal is explicit, namely news articles from Courier-Mail (pro-coal) and tweets using the hashtag

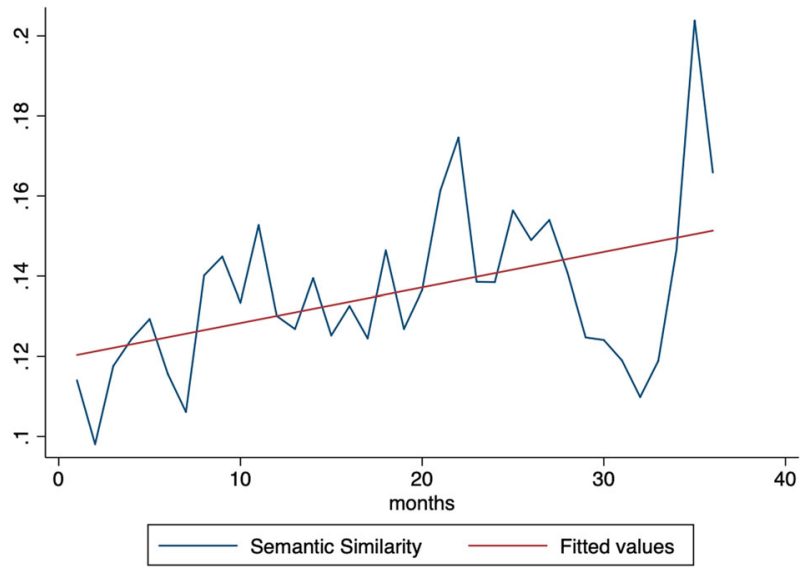

Fig. 3 The semantic similarity between explicitly anti-coal tweets using the hashtag \#StopAdani and general tweets related to Adani Carmichael has increased steadily between March 2017 and February 2020.

Semantic similarity between Adani tweets and \#StopAdani tweets, March 2017-February 2020

StopAdani (anti-coal). Results indicate that both groups of tweets have diverged from the narratives espoused by Courier-Mail. Moreover, we observed a steady increase in the semantic similarity of our two groups of tweets between March 2017 and February 2020 Hence, the discourses figuring in our group of interest (Adani tweets) have become statistically more similar to those of our control group (\#StopAdani).

Regarding the implications of greater environmental awareness in recent years, one could perhaps argue that, should this process continue, politicians will eventually respond to these demands (Dávila-Fernández and Sordi, 2020). However, the approval of the Carmichael mine notwithstanding increasing public pressure reveals that the nexus between the Australian state and the coal industry is resilient to public opinion. Consequently, it may take very long or require extraordinary levels of mobilisation for public opinion actually to affect climate policies, and there is the risk that the current economic crisis may lead to a reversal of the trend we have observed. Hence, our case study shows that explaining Australia's carbon lock-in cannot be reduced to a matter of public opinion, lobbying, and economic conditions, but should rather be approached from a broader perspective that takes into account the historical specificity of Australia's political economy and the key role of (fossil-based) energy in it.

The symbiosis between the state and the coal industry is problematic considering that historically the state has played a key role in a number of radical innovations. When investments and risks are considered too high by private investors, the visible hand of the state may be the only effective solution to the market's failure. It can crowd in private investment and foster new technologies, particularly renewable energies (Mazzucato, 2015; Mazzucato and Semieniuk, 2018), the transition to which is thus highly contingent on state participation.

While media studies often focus on traditional outlets, we have shown that the Twittersphere represents a forum of open debate and contestation about coal, even in the case of Australia where the mainstream media is highly connected with the coal industry. Opposition to coal interests is well reflected in average Twitter sentiments, and contestation has been increasing in recent years. Policymakers, whether opponents or proponents of coal expansion, are well-advised to be more attentive to the growing dissatisfaction of the public with coal-fired power in the country. Researchers, likewise, can draw important lessons from investigating narratives on social media. If we are to achieve a timely 
transition to renewable energy, public online debates will most likely be an important locus of socio-political transformation.

\section{Conclusions}

This article has studied how the coal industry is imbricated as a key link in Australia's political economy, despite growing awareness of its environmentally deleterious effects. We have shown how the coal industry occupies a central role in Australia's economy and its international insertion, which gives it structural power to influence key political dynamics in the country. We have shown how the industry enhances this structural power by conducting inside- and outside-lobbying activities, exploiting faultlines in Australia's political system to lock in its economic interests in face of varying levels of public contestation. Within outside-lobbying activities, we have zoomed into practices of discursive legitimisation, exploring how segments of the traditional media have advanced pro-coal narratives. In particular, we have shown that the corporate traditional media has consistently advanced a pro-coal agenda, which is far and growingly removed from the state-funded media and, in particular, from the dimensions of public sentiment expressed on social media. This reveals both how the corporate traditional media is part of Australia's mode of regulation, underpinning coal's key role in the latter through attempts at providing discursive legitimisation, and how this has been increasingly contested in other quarters. Methodologically, we have also demonstrated how techniques of natural language processing can be used to investigate the similarities and divergences of discourses in different media, applied to politically and environmentally sensitive topics.

There are a number of directions for further studies that arise out of our contribution, of which we highlight two. First, while we have approached the question of how incumbent industries reproduce their privileged space in Australia's political economy through a variety of mechanisms, our empirical contribution has focused on the role of different branches of the media. Further studies could investigate how the other levers of power discussed in this article, such as inside-lobbying, have changed over time, leading to a broader understanding of the shifting 'geometries of power' of the coal industry and its challenges. Second, we have focused on a single, if rather important, social media platformi.e. Twitter. Further studies could explore how different segments of public opinion and corporate strategies have moved within and between platforms, thus further broadening our understanding of the topology of struggles against, and resistance to, climate change, as well as the public policy response this has received.

Finally, our contribution has important implications for our understanding of the stakes involved in combatting climate change, in Australia and elsewhere. Our political economy approach to the question, which highlights forms of structural power, mediating institutions, and the role of-popular, corporate and political-agency in reproducing and contesting climate change, is well-positioned to avoid both fatalistic and voluntaristic answers. As such, we have highlighted the corporate media's complicity with the coal economy and how the Australian state is symbiotically linked to the latter, leading to a deep carbon lock-in in the country with global repercussions. We have also indicated how social media, inhabited by segments of the wider public and increasingly also by corporate agents, is a privileged arena to contest narratives and influence public opinion. While this analysis does not allow us to predict the probability of change occurring, it does show which spaces are more favourable battlegrounds in the struggle over popular opinion and the scale of the transformations needed to move Australia towards a net-zero economy. Crucially, these involve a deep overhaul of the country's political economy and mode of regulation, which any political process, whether directed by the state or from the bottom up, must confront in order to be effective.

\section{Data availability}

The replication materials for this paper can be found at Github at https://github.com/ayakachi/coaltweets/tree/master/Adani.

Received: 27 July 2020; Accepted: 2 June 2021;

Published online: 22 July 2021

\section{Notes}

1 Courier-Mail is owned by News Corp, listed on Nasdaq. Rupert Murdoch is the chairman and his son Lachlan Murdoch co-chairman of News Corp. The Murdoch Family Trust owns approximately $38 \%$ of voting B shares, and more information on share-ownership is given in the fourth section of the article.

2 Newman et al. (2020) show that social media has increased substantially as a source of news in surveyed countries since 2012. 2020 data indicate that, overall, 55\% of respondents used it for this purpose (above print media at $20 \%$ and radio at $30 \%$, and slightly below television, at $65 \%$ ). Online access to news, including via social media, was at $82 \%$.

3 https://github.com/ayakachi/coaltweets/tree/master/Adani

4 James Murdoch, Rupert Murdoch's son, resigned from News Corp in 2020, specifically over its coverage of climate change. Which is to say, when there is conflict over climate change in News Corp, even at the bosom of its controlling family, the strong link in the chain is its defence of coal and denial of climate change. More broadly, McKnight (2012) highlights how Murdoch's media empire has been systematically engaged in conscious manipulation of political debates in the US, misrepresentation of public opinion, and maintaining a close association to political parties, all as a strategy to advance Murdoch's political views in which climate-change denial looms large.

\section{References}

Antilla L (2005) Climate of scepticism: US newspaper coverage of the science of climate change. Glob Environ Change 15(4):338-352

Aulby H (2017) The tip of the iceberg: political donations from the mining industry. The Australian Institute Discussion Paper. 1-16

Baer H (2016) The nexus of the coal industry and the state in Australia: historical dimensions and contemporary challenges. Energy Policy 99:194-202

Bell S, Hindmoor A (2014) The structural power of business and the power of ideas: the strange case of the Australian mining tax. New Political Econ 19(3):470-486

Blondeel M, Van de Graaf T (2018) Toward a global coal mining moratorium? A comparative analysis of coal mining policies in the USA, China, India and Australia. Clim Change 150(1-2):89-101

Boykoff MT (2011) Who speaks for the climate?: making sense of media reporting on climate change. Cambridge University Press

Boykoff MT, Boykoff JM (2007) Climate change and journalistic norms: a casestudy of US mass-media coverage. Geoforum 38(6):1190-1204

BP (2019) BP statistical review of world energy. BP.

Brevini B, Woronov T (2017) Nothing but truthiness: public discourses on the Adani Carmichael Mine in Australia. In: Brevini B, Murdock G (eds). Carbon capitalism and communication. Springer, pp. 147-159.

Brym R et al. (2014) Social media in the 2011 Egyptian uprising. Br J Sociol 65 (2):266-292

Cody EM et al. (2017) Transitions in climate and energy discourse between Hurricanes Katrina and Sandy. J Environ Stud Sci 7(1):87-101

Crowley K (2013) Pricing carbon: the politics of climate policy in Australia. Wiley Interdiscip Rev-Clim Change 4(6):603-613

Cui RY et al. (2019) Quantifying operational lifetimes for coal power plants under the Paris goals. Nat Commmun 10:4759

Curran G (2020) Divestment, energy incumbency and the global political economy of energy transition: the case of Adani's Carmichael mine in Australia. Clim Policy 20(8):949-962

Curran G (2021) Coal, climate and change: the narrative drivers of Australia's coal economy. Energy Res Soc Sci 74:101955

D'Alessandro S et al. (2020) Feasible alternatives to green growth. Nat Sustain 3 (4):329-335

Dávila-Fernández M, Sordi S (2020) Attitudes towards climate policies in a macrodynamic model of the economy. Ecol Econ 169:106319

Deerwester S et al. (1990) Indexing by latent semantic analysis. J Am Soc Inf Sci 41 (6):391-407

Della Bosca H, Gillespie J (2018) The coal story: generational coal mining communities and strategies of energy transition in Australia. Energy Policy 120:734-740 
Demetrious K (2019) 'Energy wars': global PR and public debate in the 21st century. Pub Relat Inq 8(1):7-22

Edenhofer O et al. (2018) Reports of coal's terminal decline may be exaggerated. Environ Res Lett 13:024019

Farrell H (2012) The consequences of the internet for politics. Annu Rev Political Sci $15: 35-52$

Farrell J (2016) Network structure and influence of the climate change countermovement. Nat Clim Change 6(4):370

Fogel K et al. (2008) Big business stability and economic growth: is what's good for General Motors good for America? J Financ Econ 9(1):83-108

Gencsu I et al. (2019) G20 coal subsidies: tracking government support to a fading industry. ODI.

Gilens M, Page B (2014) Testing theories of American politics: elites, interest groups, and average citizens. Persp Pol 12(3):564-581

Gudynas E (2009) Diez tesis urgentes sobre el nuevo extractivismo. In: Schuldt J et al. (eds) Extractivismo, politica y sociedad. Centro Andino de Acción Popular, pp. 187-225.

Hess DJ (2014) Sustainability transitions: a political coalition perspective. Res Policy 43(2):278-283

Hillman A, Hitt M (1999) Corporate political strategy formulation: a model of approach, participation, and strategy decisions. Acad Manag Rev 24 (4):825-842

Hobbs M (2020) Conflict ecology: examining the strategies and rationales of lobbyists in the mining and energy industries in Australia. Publ Relat Rev 46 (2): 101868

Hobbs $\mathrm{M}$ et al. (2020) Turf wars: using social media network analysis to examine the suspected astroturfing campaign for the Adani Carmichael Coal mine on Twitter. J Public Aff 20(2):e2057

IEA (2019) Global energy \& CO2 status report 2019. International Energy Agency. Jessop B (2003) Putting hegemony in its place. J Crit Real 2(1):138-148

Jessop B, Sum NL (2006) Beyond the regulation approach: putting capitalist economies in their place. Edward Elgar Publishing.

Jewell J et al. (2019) Prospects for powering past coal. Nat Clim Change 9:529-597

Kim $S$ et al. (2016) Electric utilities and American climate policy: lobbying by expected winners and losers. J Public Policy 36(2):251-275

Kirsch S (2014) Mining capitalism: the relationship between corporations and their critics. University of California Press.

Mazzucato M (2015) The green entrepreneurial state. In: Scoones I et al. (eds) The politics of green transformations. Routledge, London, pp. 134-152.

Mazzucato M, Semieniuk G (2018) Financing renewable energy: who is financing what and why it matters. Technol For Soc Change 127(2):8-22

McKinnon M et al. (2019) Stakeholder relations in Australian science journalism. Public Underst Sci 28(5):554-571

McKnight D (2012) Rupert Murdoch: an investigation of political power. Allen \& Unwin.

McKnight D, Hobbs M (2013) Public contest through the popular media: the mining industry's advertising war against the Australian Labor Government. Austral J Political Sci 48(3):307-319

McKnight D, Hobbs M (2017) Fighting for coal: public relations and the campaigns against lower carbon pollution policies in Australia. In: Brevini B, Murdock G (eds) Carbon capitalism and communication: confronting climate crisis. Springer International Publishing, pp. 115-129.

McNair B et al. (2017) Politics, media and democracy in Australia: public and producer perceptions of the political public sphere. Taylor \& Francis.

Newman N et al. (2017) Reuters Institute Digital News Report 2017. Reuters Institute for the Study of Journalism.

Newman N et al. (2020) Reuters Institute Digital News Report 2020. Reuters Institute for the Study of Journalism.

Noam EM (2016) Who owns the world's media?: media concentration and ownership around the world. Oxford University Press.

Nyberg D, Murray J (2020) Corporate politics in the public sphere: corporate citizen speak in a mass media policy contest. Bus Soc 59(4):579-611

O'Neill S et al. (2015) Dominant frames in legacy and social media coverage of the IPCC Fifth Assessment Report. Nat Clim Change 5(4):380-385

Offe C, Wiesenthal H (1980) Two logics of collective action: theoretical notes on social class and organizational form. Political Power Soc Theory 1:67-115

Pearse G (2009) Quarry vision: coal, climate change and the end of the resources boom. Q Essay 33.

Phelan A et al. (2017) Evaluation of social externalities in regional communities affected by coal seam gas projects: a case study from Southeast Queensland. Ecol Econ 131:300-311
Rosenbloom D, Rinscheid A (2020) Deliberate decline: an emerging frontier for the study and practice of decarbonization. Wiley Interdiscip Rev-Clim Change: wcc. 669

Rosewarne S (2016) The transnationalisation of the Indian coal economy and the Australian political economy: the fusion of regimes of accumulation? Energy Policy 99:214-223

Steckel JC et al. (2015) Drivers for the renaissance of coal. Proc Natl Acad Sci USA 112:E3775-E3781

Steckel J et al. (2020) Coal and carbonization in sub-Saharan Africa. Nat Clim Change 10:83-88

Svampa M (2013) Consenso de los commodities y lenguajes de valoración en América Latina. Nueva Soc 44:30-46

Thurber M, Morse R (2015) The global coal market. Cambridge University Press.

Tiffen R (2015) From punctuated equilibrium to threatened species: the evolution of Australian newspaper circulation and ownership. Austral J Rev 37(1):63

Trencher G et al. (2021) Revisiting carbon lock-in in energy systems: explaining the perpetuation of coal power in Japan. Energy Res Soc Sci 69:101770

Unruh G (2000) Understanding carbon lock-in. Energy Policy 28(12):817-830

Vela-Almeida D et al. (2015) Setting the limits to extraction: a biophysical approach to mining activities. Ecol Ecosyst 119:189-196

Vorrath S (2019) Lobbyist who provided Morrison's lump of coal joins PM's advisory team. Renew Econ:19 June 2019

Weiler F, Brändli M (2015) Inside vs. outside lobbying: how the institutional framework shapes the lobbying behavior of Interest Groups. Eur J Political Res 54(4):745-766

Williams $\mathrm{H}$ et al. (2015) Network analysis reveals open forums and echo chambers in social media discussions of climate change. Glob Environ Change $32: 126-138$

Winters J, Page B (2009) Oligarchy in the United States? Perspect Politics 7 (4):731-751

Zhao $S$ et al. (2008) Identity construction on Facebook: digital empowerment in anchored relationships. Comp Hum Behav 24(5):1816-1836

\section{Acknowledgements}

This research is part of a project (COALSTAKE, The Political Economy of Coal Policy: Comparative Analyses of Stakeholder Strategies and Resource Industries' Embeddedness in the International Economy) funded by the Swiss Network for International Studies (SNIS). We would like to thank Daniel Rosenbloom and Heinrich Jakob Wild for their useful comments.

\section{Competing interests}

The authors declare no competing interests.

\section{Additional information}

Supplementary information The online version contains supplementary material available at https://doi.org/10.1057/s41599-021-00827-5.

Correspondence and requests for materials should be addressed to A.K.

Reprints and permission information is available at http://www.nature.com/reprints

Publisher's note Springer Nature remains neutral with regard to jurisdictional claims in published maps and institutional affiliations.

Open Access This article is licensed under a Creative Commons Attribution 4.0 International License, which permits use, sharing, adaptation, distribution and reproduction in any medium or format, as long as you give appropriate credit to the original author(s) and the source, provide a link to the Creative Commons license, and indicate if changes were made. The images or other third party material in this article are included in the article's Creative Commons license, unles indicated otherwise in a credit line to the material. If material is not included in the article's Creative Commons license and your intended use is not permitted by statutory regulation or exceeds the permitted use, you will need to obtain permission directly from the copyright holder. To view a copy of this license, visit http://creativecommons.org/ licenses/by/4.0/

(C) The Author(s) 2021 